\title{
Laudation to Prof. Dr. Hans-Toni Ratte-towards conceptual, theory-based ecological science and its transfer to the applied field of ecotoxicology
}

\author{
Theo Brock ${ }^{1}$, John P Giesy ${ }^{2}$, Fred Heimbach ${ }^{3}$, Henner Hollert ${ }^{4 *}$, Martina Roß-Nickoll ${ }^{4}$, Andreas Schäffer ${ }^{4}$ and \\ Klaus Günther Steinhäuser ${ }^{5}$
}

\begin{abstract}
In order to thank Prof. Dr. Hans-Toni Ratte on the occasion of his retirement for his outstanding experimental and modelling merits in the field of ecotoxicology and ecology and his personal 65th anniversary on November 25th this article will present a laudation.
\end{abstract}

Keywords: ecology, ecotoxicity, modelling

\section{Laudation Theo C.M. Brock}

Dr. Theo C. M. Brock

Alterra, Wageningen University and Research Centre

P.O. Box 47, 6700 AA, Wageningen

The Netherlands

Prof. Dr. Hans Toni Ratte: A pioneer in mechanistic effect modelling and an excellent lecturer. More than 20 years ago, Drs. Hans Toni Ratte and Peter Leeuwangh organized a German-Dutch meeting in Ecotoxicology that took place at RWTH Aachen University. As a junior scientist with a $\mathrm{PhD}$ degree in Aquatic Ecology, and hardly no international network in the field of environmental risk assessment, I was honoured with the invitation to present my post-doc research on the ecological impact of the insecticide chlorpyrifos in indoor freshwater microcosms. I considered this meeting as a milestone of my beginning career as aquatic ecotoxicologist. At this German-Dutch meeting, representatives of different stakeholder groups (academia, regulators, industry, consultants) were present, many involved with the environmental risk assessment of pesticides. Here, I realized the importance of applied environmental research and its direct use in decision making. Here, I also met for the first time Hans Toni Ratte, a respected colleague with a broad scientific interest covering topics

\footnotetext{
* Correspondence: Henner.Hollert@bio5.rwth-aachen.de

${ }^{4}$ RWTH Aachen University, Institute for Environmental Research (Biology V), Worringerweg 1, 52074 Aachen, Germany

Full list of author information is available at the end of the article
}

like applied ecology [1-3], ecotoxicology [4-7], ecotoxicological statistics $[8,9]$, mechanistic effect models [10], and guidance development [11].

Within the scientific community it is more and more recognized that the extrapolation of results from laboratory toxicity experiments to complex field communities requires the analysis of the interactions between different trophic levels in ecosystems, which can be done by means of model ecosystems and mechanistic modelling. Within this context it is worthwhile mentioning that already in the early 1990s of the past century Hans Toni Ratte started with the supervision of a research project at RWTH Aachen University to integrate and extrapolate ecotoxicological experiments by means of model ecosystem research and computer simulation models $[10,12,13]$. Looking back, it is fair to say that Hans Toni was far ahead of his time. It took almost 20 years before the development of mechanistic simulation models as useful higher-tier tools in the effect assessment of toxicants became broadly supported by different stakeholder groups (e.g. the EU CREAM research programme [14]; the MEMoRisk working group of SETAC [15]). Although it may have been frustrating for Hans Toni that for a long time effect models in environmental risk assessment were only reluctantly accepted, it certainly will enjoy him that now his students play an active role in the promoting and further development of effect models as tools for higher-tier risk assessment [16-18]. 


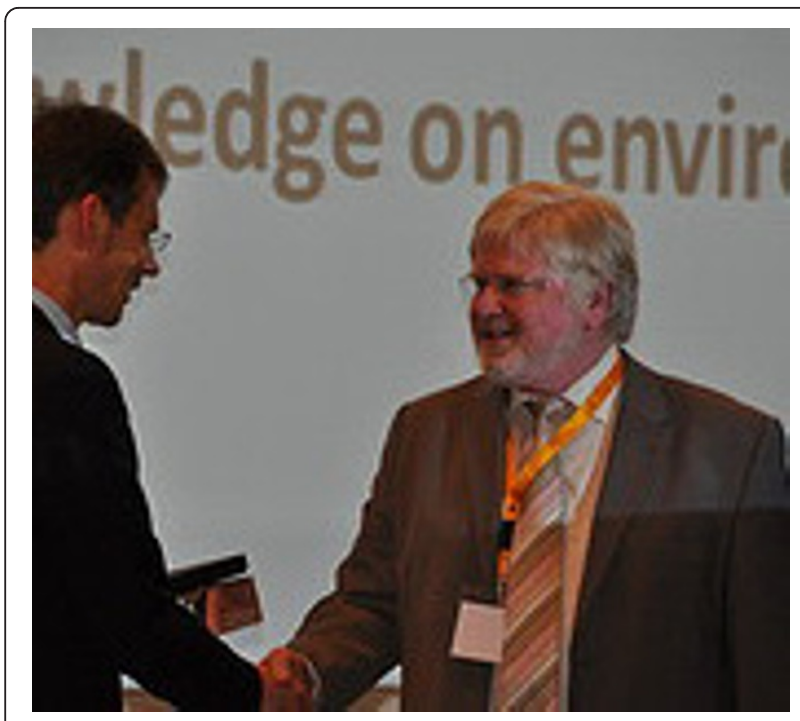

Figure 1 In 2010, Hans Toni Ratte was awarded by SETAC with the very prestigious international SETAC Environmental Education Award.

In 2010, I had the honour to introduce Prof. Dr. Hans Toni Ratte as the winner of the SETAC Europe Environmental Education Award during the Plenary Session of the annual SETAC Europe conference in Seville, Spain (Figure 1).

He received this award because of his strong dedication to education and training in environmental sciences. Among the best professional qualities of Hans Toni are without doubt his motivating teaching skills, not only as university teacher and $\mathrm{PhD}$ supervisor at RWTH Aachen University, but also as lecturer at international/external university courses (Coimbra; Bilbao; EU Marie-Curie Training) and at postgraduate training courses for governmental agencies, contract labs and chemical industry. Hans Toni Ratte also received this award because he is considered an excellent mentor who stimulated, and still stimulates, students and young scientists to actively participate in workshops and meetings. For example, young environmental scientists find an excellent forum to discuss their research in meetings of the SETAC German Language Branch, of which Hans Toni Ratte was one of the founders. Also in his role as SETAC Europe President and council member Hans Toni always stimulated young scientist to play an active role in co-chairing and organizing sessions during annual meetings (Figure 2).

Dear Hans Toni, thanks for the stimulating role you played by transferring your skills and inspiring enthusiasm to the younger generation, and by facilitating the translation of scientific knowledge for its use in decision making. Last but not least, thanks for the friendship you generously offered, and of course also for your humour and wit that made our contacts always a pleasant experience.

\section{Laudation Fred Heimbach}

Dr. Fred Heimbach, Am Rauenbusch 13, 42799 Leichlingen, Germany

Email address: fred.heimbach@t-online.de

Formerly: Bayer CropScience

Dear Toni,

After many years you now have to say "good bye" to your esteemed university. We both have been close friends during all your years at university, starting from

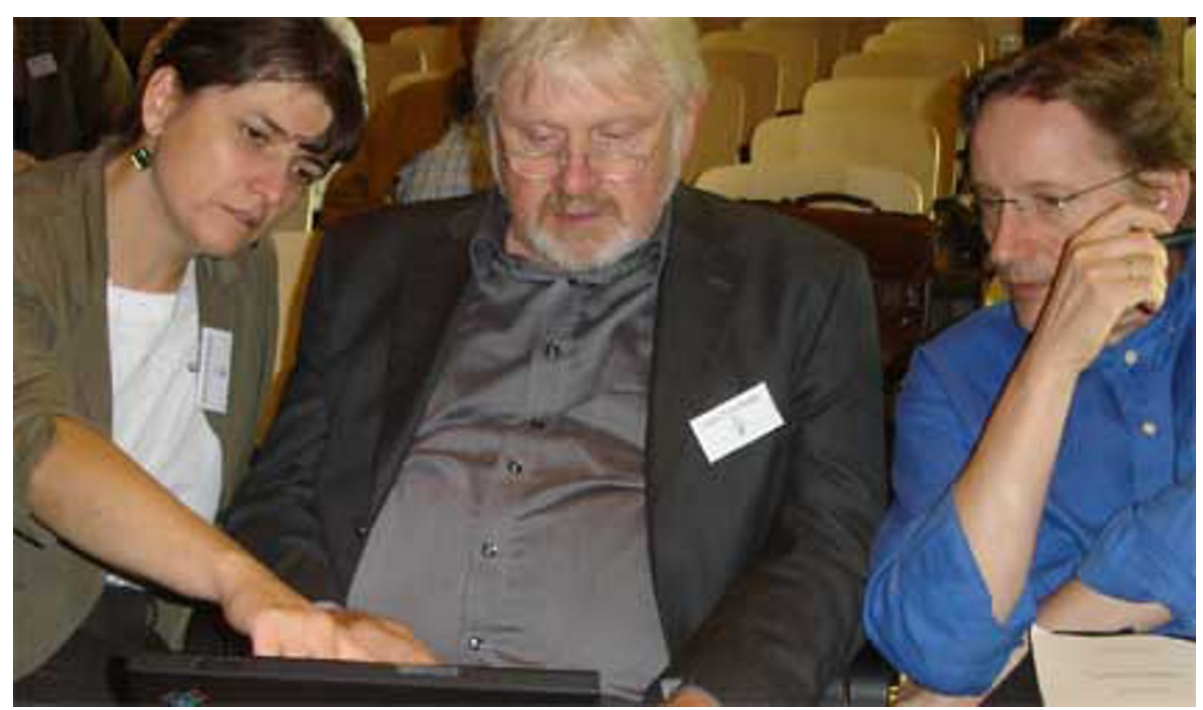

Figure 2 Toni Ratte during a SETAC Europe Annual meeting (left: Martina Roß-Nickoll, right: Andreas Schäffer). 
the early beginning as young students in the late 1960s at the University of Cologne (Germany). Thereafter, we began to learn basic science during the years working for our master- and PhD-thesis. We experienced from the early beginning the value of team working and cooperation. While I joined industry nearby some years later, you went $50 \mathrm{~km}$ westwards to the Technical University of Aachen (Germany)-where you stayed until today. Both of us entered a new emerging scientific topic which is nowadays usually called "ecotoxicology". However, longlasting and controversial discussions dominated the first of these years, since basic principles and rules for interpretation and acceptance of findings were lacking (an issue which is unfortunately still ongoing). I will never forget our (and others') discussions on acceptability of cooperation's between industry and universitywhich we considered as the way forward to address ongoing environmental issues. Thank you, Toni, for not giving up. Luckily, such cooperation's are well accepted nowadays. We then also got in contact with the North American scientific society SETAC, the "Society of Environmental Toxicology and Chemistry". Both of us considered that this scientific society can really provide a forum for scientists like us to discuss ongoing environmental topics and issues in order to move forward. You managed to assist SETAC to spread over to and to get established in Europe: this was the first step of this organization to expand to other continents, while SETAC today is a really global organization. During all these years, you actively contributed to and influenced the ongoing scientific discussions on ecotoxicology, from the basic principles of a tiered approach to hazard and risk assessment procedures, from single species laboratory testing through mesocosm studies to population modelling. (By the way: is there something really new? Didn't we discuss all these topics already years ago-although we did not know by then how to handle and to address the questions and ideas properly?)

You and I faced major problems in our scientific career. The overcoming of these problems helped to grow-there is no success without facing and solving major problems. That's true for you and me-and many others.

Toni, I'm thankful for our long-term friendship from student years until retirement. Congratulations to your success within the scientific arena of ecotoxicology. Without your contributions, ecotoxicology would not be what it is today. You really deserve the different awards and the recognition of colleagues from all around the globe. It's their duty to appreciate your scientific contributions. However, I'd like to restrict myself to honour a part of your life which is even more important to me. I'm most thankful for all the many years working together as friends. I hope you now will enjoy many more years with distinctly more time for your family, for fishing and honey bees, and-last but not least-for your new and old friends.

All the best

FRED

\section{Laudation John P Giesy}

Prof. John P. Giesy, Ph.D., FRSC

Professor \& Canada Research Chair in Environmental

Toxicology

Department of Veterinary Biomedical Sciences

University of Saskatchewan

44 Campus Drive

Saskatoon, SK S7N 5B3, Canada

Concurrent positions:

Emeritus Distinguished Professor of Zoology, Michigan State University

Honorary Professor, School of Biological Sciences, The University of Hong Kong

Chair Professor at Large, Dept. Biology and Chemistry, City University of Hong Kong

Concurrent Professor, School of Environment, Nanjing University

Visiting Professor, Xiamen University

Einstein Professor, Chinese Academy of Science

Distinguished Honorary Professor, King Saud University

Tony Ratte, a friend for the ages.

Herr. Doktor, Professor und Direktor Anthony Ratte, it is hard to believe that you are retiring from your post as professor at the university. It does not seem possible. Hey, retirement is easy! I have done it three times!!!!! I hope people do not catch on that I am just doing it for the parties.

We go back a long time and I remember when we were both young and building our careers you were very kind to me. I do not really remember our first meeting, it is shrouded in the mists of time, but I do remember visiting you with my family in Aachen. It might have been when I was a Fulbright Fellow in the mid 1980s, so it must have been almost 30 years ago. But I do remember your warm hospitality and the zeal with which you toured me around Aachen and taught me so much. I remember touring the laboratories and hearing about your mesocosm studies and the desire to link basic population, community and ecosystem studies with toxicology. Your zest for life and passion for the science were infectious. I think we knew of each other from the literature since I also did work with mesocosms in my early career. But, what I remember most was feeling at ease with you and I liked you instantly and that feeling has never changed over the past 30 years. You have remained a loyal friend and we have had a lot of fun together whether it was at meetings or 
times when you visited me in Michigan and then here in Canada. We have always enjoyed each other's company.

Tony, while I prize your friendship greatly, that is not all that you gave to me. Over the years, you have sent several Ph.D. students and post docs to my laboratory. I always appreciated that you entrusted them to me because I know how much you care about the students. They were always well prepared and top quality people. Each and everyone was very productive, and diligent, but also very kind and to all became more than just colleagues-they became friends and are still friends to this day and I still interact with them at meetings. That heritage that we started all those years ago continues to the present day through cooperations with Henner Holert, and as I type this note, students from Aachen are working in the laboratory here at the University of Saskatchewan. So I would have to say that the cooperation with Aachen is among the longest running of any I have had. It has also been one of the most productive from a scientific point of view. I do not know how many papers we published together over the years, but each was significant in its' own way and some have become classics with very high rates of citation. What I do know is that I have learned from each project and enjoyed the people with whom I have had the opportunity to work. It has been something special. These times are always bitter sweet for all of us. When we retire from one profession that has been such a huge part of our lives, it is a bit sad. But, it is also a time to stop and reflect on all of the accomplishments and peoples' lives whom you have touched, including mine and take satisfaction and of course some pride in what was accomplished. It is a time to take stock and I think the score card is pretty full. I would say, you have earned the opportunity to spend some time doing other things that you love to do and in addition to being a researcher, educator and scholar. Now you can devote more time to your bees and your fruit trees and make honey and wine and other great taste sensations.

However, while you will be off tending to your other passions of life, I expect that you will not abandon science, because scientist is not what you do, it is what you are. So I expect you will still be asking questions and doing experiments, just not at the university. I also expect that you will remain active in sharing your knowledge and perspective to environmental issues and sharing that knowledge with your people and imbuing in them the strong environmental ethic and moral compass that has sustained you through the years. You still have a lot to offer the world and I know you will continue to do so, but in different ways. I still hope to see you at conferences and workshops and to have a change to discuss current issues with you.
Tony, I have been fortunate to have had a long and interesting career. While the science has been interesting, it is the people that have come into my life that have made it special and you are one of the most special of the special. I do not feel like I have worked a day in my life. Every day is interesting and a challenge in its' own way, but I get to go to interesting places and see interesting things and meet interesting people-people like Tony Ratte. It is my privilege and an honour to call you my colleague, but most important to me is to call you my friend.

So my friend, on the occasion of your transition from one avocation to others, I wish you all the best. May the sun and the wind always be at your back and may you have many, many years to enjoy your passions and spread the joy that is to know Tony Ratte. May you get to do all of the things on your list that have not yet been accomplished or sampled and may your life be as sweet as the honey you make. I am glad that you came into my life-I know I am a better person for having known you.

My wife and your friend Susan and I have taken a moment on this Saturday evening to raise our glasses in a Toast to our dear friend Tony. We make that toast with a very special bottle of Aufgeselzler made from Johannisbeeren by the Hand of Tony Ratte in July of 2007. It is a very special memento that we keep for only the most special of occasions.

Here is to you my friend.

John P. Giesy, Ph.D., FRSC

Saskatoon, Saskatchewan, Canada

October 1, 2011

\section{Laudation Klaus Günter Steinhäuser}

Prof. Dr. Klaus Günter Steinhäuser

Federal Environment Agency

Wörlitzer Platz 1

06844 Dessau-Roßlau, Germany

Dear Toni,

How will the chemical safety division of the German Federal Environment Agency live without your experience and advice? We have learnt a lot from you, e.g. Why should we look at the rate and not at the biomass in algal and microbial ecotoxicology? How can we use ecotoxicological test results for environmental modelling? How is biodiversity alongside fields influenced by herbicide treatment? Why is an ECx advantageous compared with a NOEC? The fascinating aspect of your personality is that you are an excellent teacher but never are indoctrinating. It is due to you that regulatory ecotoxicology today is far more than the application of legal rules and guidance notes. We learnt from you how to link biotesting with applied ecology and environmental modelling, how we can expand our knowledge from 
single species tests in the laboratory to micro- and mesocosms and their dynamics. Many of my co-workers visited your courses at RWTH and took great profit from it. This is outstanding and now-facing your retirement-it is time to thank you warmly.

In addition, I want to note that you were one of the founders of SETAC GLB branch. Can we today imagine the times without this forum which became the most important for the scientific exchange between university, industry and governmental institutions?

I got to know you in 1993 when we both were members of the DIN group "biotests". We planned to amend the general advice how to conduct aquatic biotests and established a small group consisting of you, Ernst Nusch, Wolfgang Bödeker and me in order to draft a chapter how tests should be designed, carried out and evaluated. We were extremely productive. You taught us statistics and explained the contexts in a fashion that could be readily understood by ecotoxicologists who avoided mathematics since there studies at university. This fascinating cooperation established the basis for a friendship between us lasting for many years. I remember several times we met after this activity and discussed several topics at the interface between science and regulation and I always appreciated your ability to listen advertently.

Toni, I am sure that we will not lose each other after your retirement. We will miss you but I am also convinced that we will hear your voice with interesting and wise statements from time to time. Now you will have more time for your bees and fruit trees. Enjoy your life for many years and be proud of that what you have given your students, friends and colleagues!

I wish you all the best

Klaus

\section{Laudation Martina Roß-Nickoll, Henner Hollert and Andreas Schäffer}

Dr. Martina Roß-Nickoll, Prof. Dr. Henner Hollert and Prof. Dr. Andreas Schäffer

Institute for Environmental Research (Biology V)

Worringerweg 1, 52074 Aachen, Germany

Hans Toni Ratte, a major pillar of the Institute for Environmental Research at RWTH Aachen University http://www.bio5.rwth-aachen.de, is a very successful teacher and experimental researcher in the field of ecotoxicology and aquatic ecology. He entered RWTH Aachen in 1979 together with Prof. Heinrich Kaiser, a theoretical ecologist and pioneer in individual-based modelling. Toni was always interested in conceptual, theory-based science and transferred this to the applied field of ecotoxicology always paying much attention to the ecological base of this research field. He became an expert in mathematical modelling of ecotoxicological processes such as the individual-based daphnia model describing the effect of pollutants on population dynamics. In addition, he became a well-known and excellent expert in statistical evaluation of ecotoxicological datasets. From this experience, he developed the ecotoxicological statistics program ToxRat nowadays used in many countries of the world.

Toni is an enthusiastic teacher with an enormous spectrum of knowledge in ecology and ecotoxicology, both in lecturing and organizing practical courses and student excursions. The latter, run in several places in Germany, Sweden, Norway, and Italy, were very well accepted by the students because he always looked for a diligent mixture of scientific education and a program with specific trips to enjoy the nature, landscape and wild-life as well as the culture of the visited countries (Figures 3, 4, 5, 6, 7).

In the team of our institute, he was the major driving force to plan a new master program for ecotoxicology which has started in 2009. This program comprises all relevant fields of biology and chemistry-based environmental research and is well accepted by the students who earn a sound base for later positions in industry, authorities and research institutes.

In 2003, the institute gaiac was founded as a spin-off company http://www.gaiac.rwth-aachen.de and research institute affiliated to the RWTH Aachen University with a focus on the effects of anthropogenic influences on aquatic and terrestrial biocoenoses. The institute recruits its staff mainly from previous students of our institute, many of which (in total he supervised $30 \mathrm{PhD}$ students and many more than 100 diploma, bachelor and master students) were trained by Toni. He again contributed significantly in this idea and serves in the board of the small and medium enterprise gaiac.

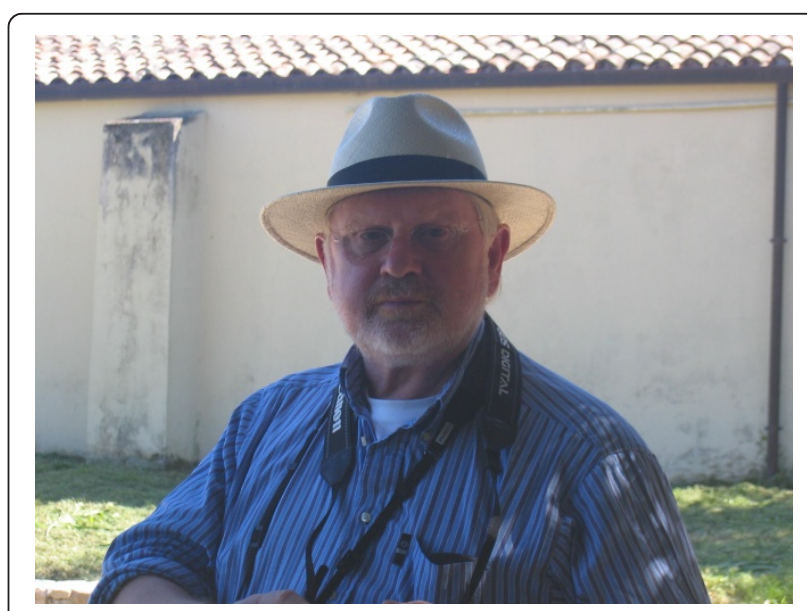

Figure 3 Toni during a practical course in Sardegna. 

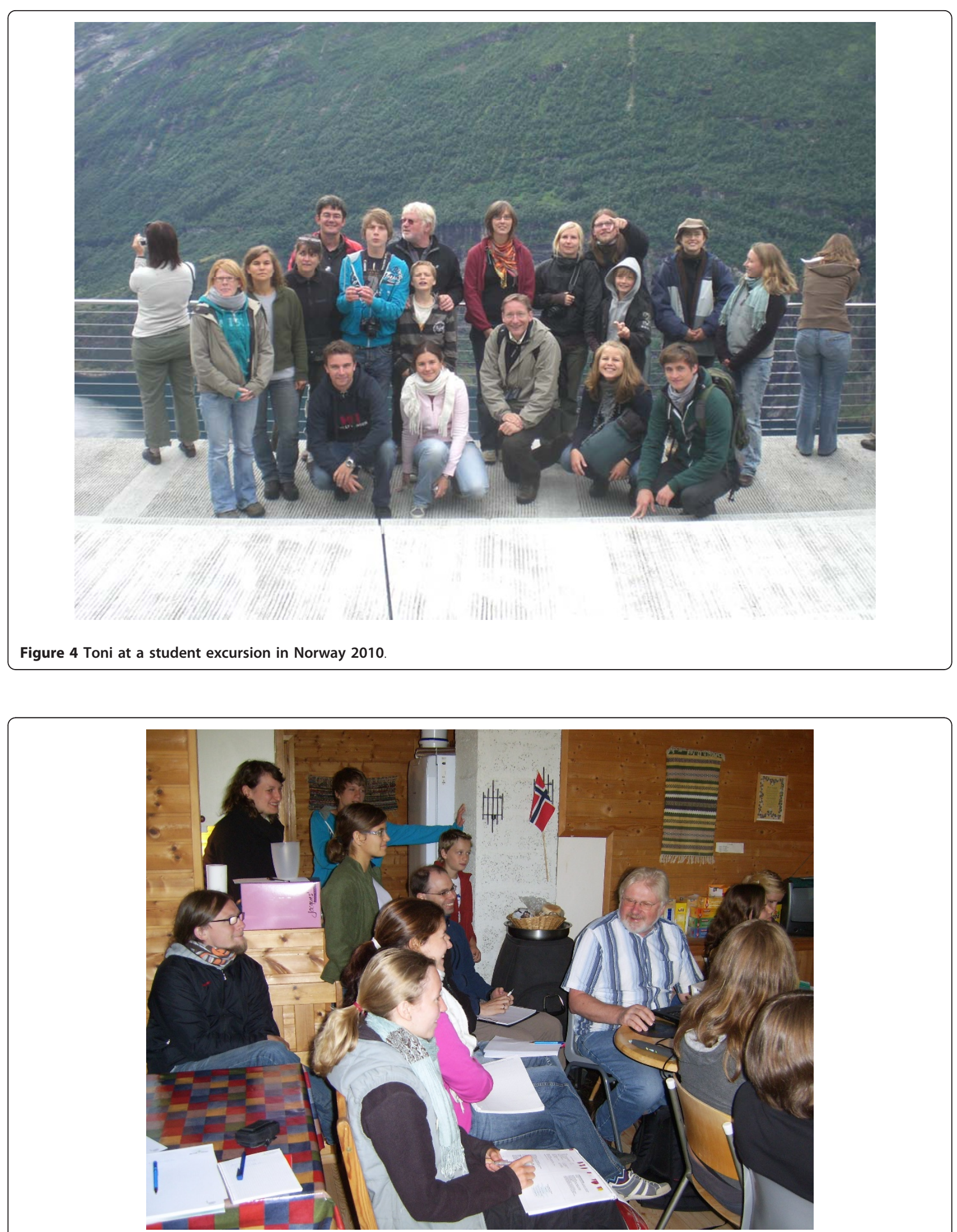

Figure $\mathbf{5}$ Toni at a student excursion in Norway 2010 giving a lecture on ecology of fish. 


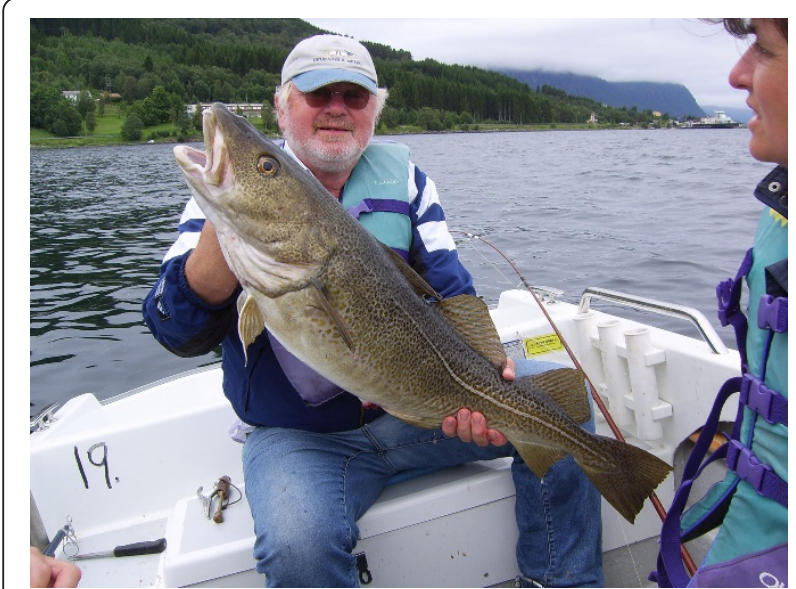

Figure 6 Toni at a student excursion in Norway 2010 convincing with his practical skills on fish biology.

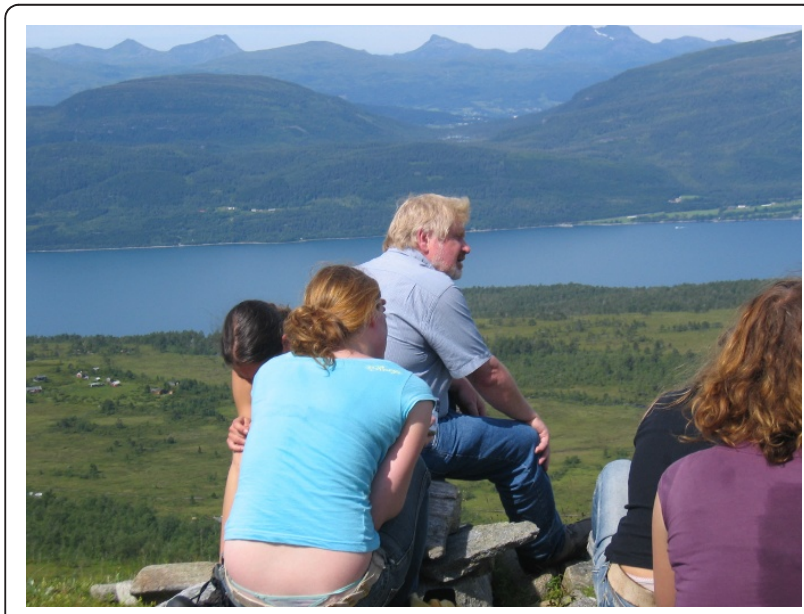

Figure 7 Toni at a student excursion in Norway 2010

Toni was one of the major players of the international organization Society of Environmental Toxicology \& Chemistry (SETAC) and served as president of SETAC Europe in 1998-1999. Recently, in 2010, he was awarded by SETAC with the very prestigious international SETAC Environmental Education Award. In addition, he was one of the founders and the first president of the SETAC German language branch which awarded him for its outstanding contributions to the society in 2007 as an honorary member. He was one of the main players in establishing a Germany-wide post graduate program in Ecotoxicology hosted by the SETAC German language branch and the German Society of Chemistry (GDCh).

Toni is one of the most insightful and creative minds that we have had the pleasure to know. He always was aware that for a successful research and teaching atmosphere it is very important to realize a friendly atmosphere, to carefully listen to the others, to respect alternative views and to allow the freedom of exploring new directions.

We thank Toni for his great performance and support in our team. We lose a marvellous colleague and a very good friend but our friendship will continue for sure.

We wish you all the best

Martina, Henner and Andreas

\section{Author details}

'Alterra, Wageningen University and Research Centre, P.O. Box 47, 6700 AA, Wageningen, The Netherlands ${ }^{2}$ Department of Veterinary Biomedical Sciences, University of Saskatchewan, 44 Campus Drive, Saskatoon SK S7N 5B3, Canada ${ }^{3}$ Am Rauenbusch 13, 42799 Leichlingen, Germany (formerly Bayer Cropscience ${ }^{4}$ RWTH Aachen University, Institute for Environmental Research (Biology V), Worringerweg 1, 52074 Aachen, Germany ${ }^{5}$ German Federal Environment Agency, Wörlitzer Platz 1, 06844 Dessau-Roßlau, Germany

\section{Authors' contributions}

$\mathrm{HH}$ developed the concept of this laudation. TB, JPG, PG, FH, MRN, HH and AS contributed equally to the content of the laudation and gave their final approval. All authors read and approved the final manuscript.

\section{Competing interests}

The authors declare that they have no competing interests.

Received: 2 November 2011 Accepted: 10 November 2011 Published: 10 November 2011

\section{References}

1. Büns M, Ratte $H T$ : The combined effects of temperature and food consumption on body weight, egg production and development time in Chaoborus crystallinus De Geer (Diptera: Chaoboridae)-some new evidence for the adaptive value of vertical migration. Oecologia 1991, 88:470-476.

2. Goser B, Ratte HT: Experimental evidence of negative interference in Daphnia magna. Oecologia 1994, 98:354-361,

3. Klüttgen $B$, Dülmer $U$, Engels $M$, Ratte $H T$ : $A D a M$, an artificial freshwater for the culture of zooplankton. Water Res 1994, 28:743-746.

4. Hammers-Wirtz M, Ratte HT: Offspring fitness in Daphnia: is the Daphnia reproduction test appropriate for extrapolating effects on the population level? Environ Toxicol Chem 2000, 19:1856-1866.

5. Ratte HT: Bioaccumulation and toxicity of silver compounds: a review. Environ Toxicol Chem 1999, 18:89-108.

6. Cleuvers M, Ratte HT: Phytotoxicity of coloured substances: is Lemna Duckweed an alternative to the algal growth inhibition test? Chemosphere 2002, 49:9-15.

7. Coors A, Jones PD, Giesy JP, Ratte HT: Removal of estrogenic activity from municipal waste landfill leachate assessed with a bioassay based on reporter gene expression. Environ Sci Technol 2003, 37:3430-3434.

8. Hommen $\mathrm{U}$, Veith $\mathrm{D}$, Ratte $\mathrm{HT}$ : A computer program to evaluate plankton data from freshwater filed tests. In Freshwater Field Tests for Hazard Assessment of Chemicals. Edited by: Hill IR, Heimbach F, Leeuwangh P, Matthiesen P. Boca Raton, FL: Lewis Publishers; 1994:503-513.

9. Ratte HT, Hammers-Wirtz M, Cleuvers M: Ecotoxicity testing. Trace Met Contamin Environ 2003, 6(C):221-256.

10. Ratte HT, Poethke HJ, Duelmer U, Hommen U: Modelling of aquatic field tests for hazard assessment. In Freshwater Field Tests for Hazard Assessment of Chemicals. Edited by: Hill IR, Heimbach F, Leeuwangh P, Matthiesen P. Boca Raton, FL: Lewis Publishers; 1994:399-423.

11. Giddings JM, Brock TCM, Heger W, Heimbach F, Maund SJ, Norman S, Ratte H-T, Schäfers C, Streloke M, (Eds): Community-level aquatic system studies-interpretation criteria (CLASSIC) Pensacola (FL): SETAC; 2002, 44.

12. Seitz A, Ratte HT: Aquatic ecotoxicology: on the problems of extrapolation from laboratory experiments with individuals and 
populations to community effects in the field. Comp Biochem Physiol C Pharmacol 1991, 100:301-304.

13. Hommen U, Poethke H-J, Dulmer U, Ratte HT: Simulation models tor edict ecological risk of toxins in freshwater systems. ICES J Mar Sci 1993, 50:337-347.

14. Grimm V, Ashauer R, Forbes V, Hommen U, Preuss TG, Schmidt A, Van den Brink PJ, Wogram J, Thorbek P: CREAM: A European project on mechanistic effect models for ecological risk assessment of chemicals. Environ Sci Pollut Res 2009, 16:614-617.

15. Preuss TG, Hommen U, Alix A, Ashauer R, Van den Brink P, Chapman P, Ducrot V, Forbes V, Grimm V, Schäfer D, Streissl F, Thorbek P: Mechanistic effect models for ecological risk assessment of chemicals (MEMoRisk)-a new SETAC Europe Advisory Group. Environ Sci Pollut Res 2009, 16:250-252.

16. Hommen U, Ashauer R, Van den Brink P, Caquet T, Ducrot V, Lagadic L, Ratte HT: Extrapolation methods in aquatic effect assessment of timevariable exposures to pesticides. In Linking Aquatic Exposure and Effects: Risk Assessment of Pesticides. Edited by: Brock TCM, Alix A, Brown CD, Capri E, Gottesbüren BFF, Heimbach F, Lythgo CM, Schulz R, Streloke M. Boca Raton, FL: SETAC Press 2010:211-242.

17. Jager T, Albert C, Preuss TG, Ashauer R: General unified threshold model of survival-a toxicokinetic-toxicodynamic framework for ecotoxicology. Environ Sci Technol 2011, 45:2529-2540.

18. Preuss TG, Hammers-Wirtz M, Ratte HT: The potential of individual based population models to extrapolate effects measured at standardized test conditions to relevant environmental conditions-an example for 3,4dichloroaniline on Daphnia magna. J Environ Monit 2010, 12:2070-2079.

doi:10.1186/2190-4715-23-34

Cite this article as: Brock et al.: Laudation to Prof. Dr. Hans-Toni Rattetowards conceptual, theory-based ecological science and its transfer to the applied field of ecotoxicology. Environmental Sciences Europe 2011

23:34.

\section{Submit your manuscript to a SpringerOpen ${ }^{\circ}$ journal and benefit from:}

- Convenient online submission

- Rigorous peer review

- Immediate publication on acceptance

- Open access: articles freely available online

- High visibility within the field

- Retaining the copyright to your article

Submit your next manuscript at $\gg$ springeropen.com 